\title{
18 \\ PSYCHOPATHY, AGENCY, AND PRACTICAL REASON
}

\author{
Monique Wonderly
}

Psychopaths exhibit a philosophically interesting combination of deficits and rational competences. They appear perfectly capable of basic means-end reasoning. They typically perform at or above average on intelligence tests, and many are quite adept at employing sophisticated forms of reasoning in order to skillfully manipulate others. Still, psychopaths seem profoundly impaired in at least one important domain of practical reasoning, moral reasoning. Many theorists have argued that psychopaths lack the capacity to competently recognize and/or respond to moral reasons.

Theorists specify and explain this impairment in a variety of ways. Some afford explanatory roles to certain emotional abnormalities, such as difficulties empathizing or experiencing negative affects. Others point to deficits that are not necessarily construed as emotive, such as an inability to recognize the interests and/or authority of others as intrinsically reason-giving, an inability to value, insufficiently unified agency, lack of self-control, or general learning deficiencies. As theorists have noted, many of these features are not merely relevant to moral reasoning, but they also bear on the capacity for practical reasoning more broadly.

Philosophers have urged that considerations about the psychopath's capacity for practical rationality can help to advance some metaethical debates. These debates include the role of rational faculties in moral judgment and action, the relationship between moral judgment and moral motivation, and the capacities required for morally responsible agency. In what follows, I discuss how the psychopath's capacity for practical reason features in these debates, and I identify several takeaway lessons from the relevant literature. Specifically, I show how the insights contained therein can illuminate the complex structure of practical rationality, inform our standards for an adequate theory of practical reason, and frame our thinking about the significance of rational capacities in moral theory and social practice.

\section{Psychopathy}

Let's first consider what the term $p$ sychopath is meant to capture. ${ }^{1}$ We are not, for example, interested in the "psychopath" that we often find in popular cinema: the blood-thirsty sadist, bent on doing evil for evil's sake. Actual psychopaths are rarely so committed and not especially sadistic. However, they typically do engage in dangerous, and sometimes violent, behavior. 
Psychopathy is a personality disorder that involves a tendency toward antisocial behaviors (e.g., threatening behavior such as verbal abuse or violence, repeated criminal conduct) and certain emotional-interpersonal deficits (e.g., shallow affect, lack of empathy, inability to feel guilt). The most commonly used diagnostic tool for identifying psychopathy is a revised version of the Psychopathy Checklist (PCL-R). The PCL-R scores subjects according to the extent that their behaviors and attitudes reflect the twenty items on the checklist. The items - characteristics such as superficial charm, callousness, impulsivity, grandiose sense of self-worth, manipulative behavior, lack of realistic long-term goals, delinquency, and so on - are measured on a 0-2 point scale, and a score of 30 suffices for a psychopathy diagnosis. The average person scores about 4. Psychopaths make up less than one percent of the total population, and the vast majority are male (Kiehl and Buckholtz 2010). ${ }^{2}$

Psychopaths do not usually suffer from compulsions, delusions, or any obvious intellectual impairments. They can be brilliant and charismatic. Some are successful at evading criminal prosecution and occasionally achieve positions of wealth and power. In some respects, psychopaths blend in with society rather well. But they diverge in others. They are quick to anger and often lash out fiercely when others interfere with their aims. They are also known to coolly and remorselessly employ violence as a means to achieving their goals (Blair 2008).

Though psychopaths are sometimes superficially charming, they are often considered incapable of (and uninterested in) meaningful relationships. According to some clinicians, they lack the capacity to love (Cleckley 1976; Hare 1993). Despite their egocentricity and intelligence, they often engage in impulsive behavior that is not only harmful to others but antithetical to their own interests. Robert Hare offers an example of such behavior when he describes the actions of one psychopath who decided to stop for beer on his way to a party but realized he'd forgotten his wallet. Hare explains, "Not wanting to walk back, he picked up a heavy piece of wood and robbed the nearest gas station, seriously injuring the attendant" $(1993,59)$.

While psychopaths perform comparatively well on most cognitive measures - including IQ tests and (some) moral reasoning tasks, they have tended to do poorly on one task that four yearold children tend to perform with relative ease, Elliot Turiel's Moral/Conventional Distinction Task (MCT). The MCT measures one's ability to distinguish between moral and conventional norms, where transgressions of the former are taken to be more serious, less permissible, and less authority dependent (Turiel 1983). Examples of typical moral transgressions include hair pulling and hitting, while examples of conventional transgressions might include drinking soup from the bowl and wearing pajamas to school. Although recent research indicates that psychopaths perform relatively well on a modified version of the MCT, earlier studies suggest that psychopaths have considerable difficulties identifying the relevant distinction (Blair 1995). ${ }^{3}$

Certain conversational oddities seem to reflect peculiar gaps in the psychopath's understanding. Consider one psychopath who, having just described how he kidnapped a woman, repeatedly raped her, and slit her throat, said to his interviewer: "Do you have a girl? Because I think it's really important to practice the three C's: caring, communication and compassion. That's the secret to a good relationship. I try to practice the three C's in all my relationships" (Kiehl and Buckholtz 2010, 25). Another psychopath referred to his mother as the "most beautiful person in the world," confessed to stealing her jewelry as a child, and then added, "You know, I never really knew the bitch - we went our separate ways" (Hare 1993, 40).

While psychopaths often use moral and emotional terms, their conversational exchanges often suggest that they don't really understand the concerns and emotional experiences of others. One psychopath boasted about how he benefitted his rape victims: "There'd be interviews with the victims. They'd get their names in the paper. Women, for example, would say nice 
things about me, that I was really polite and considerate, very meticulous . . . Some of them thanked me" (Hare 1993, 43). Or again, consider the words of another rapist, high on the PCLR, who admitted confusion over his victim's feelings: “They are frightened, right? But, you see, I don't really understand it. I've been scared myself, and it wasn't unpleasant” (ibid, 44).

These apparent deficits in understanding distinguish psychopaths from average violent criminals. To this, we can add that psychopaths also frequently exhibit distinctive physiological abnormalities. They show reduced responsiveness to emotional stimuli and often fail to exhibit the normal bodily reactions associated with registering the need to reverse one's behavior in light of negative outcomes (Blair 2008). Some imaging studies suggest that psychopaths have underdeveloped neural structures in brain areas involved in processing emotions, motivation, and self-control (Kiehl and Buckholtz 2010, 27).

With this sketch in hand, we can now turn to the role of the psychopath's capacity for practical reason in philosophical discourse.

\section{Psychopathy and practical reason in philosophical discourse}

As I indicated in the introduction, considerations about the psychopath's capacity for practical reason have featured in at least three domains of philosophical investigation: (1) the role of rational faculties in moral judgment and action, (2) the relationship between moral judgment and moral motivation, and (3) the capacities required for morally responsible agency. The first area concerns the dispute between moral rationalists and moral sentimentalists. The second concerns the debate between motivational judgment internalists and motivational judgment externalists. And the third concerns two competing views about the capacities required for moral responsibility: the rational competence view and the moral competence view.

\subsection{Moral rationalism and moral sentimentalism}

The debate between moral rationalists and moral sentimentalists is a nebulous one. Historically, it has concerned the order of priority, and respective roles, of reason and emotion in morality. As some have framed the guiding question: Is morality more like math or beauty (Gill 2007)?

Moral rationalism is associated with the claim that morality is a species of practical rationality. As Jeanette Kennett helpfully puts the point, moral rationalists are minimally committed to the claims that certain rational capacities are essential to moral agency and moral judgments are judgments about reasons - that is, in judging it wrong to $\Phi$, an agent takes herself to have identified a consideration that counts against $\Phi$-ing $(2010,251){ }^{4}$

Moral sentimentalists, on the other hand, typically afford pride of place to sentiment and emotional capacities in moral judgment and action. Some argue that empirical facts about psychopathy support a sentimentalist, rather than a rationalist, view of morality. The psychopath appears to be morally impaired, despite having (what are often taken to be) intact rational abilities. Given psychopaths' well-documented emotional deficits, sentimentalists can easily explain this, but not so for moral rationalists. Or so the challenge goes.

Jesse Prinz (2006), for example, advances a view on which emotions are both necessary and sufficient for moral judgments, adducing findings about psychopathy to support the necessity claim. He characterizes psychopathy as "the perfect test case" for the thesis that emotions are necessary for moral development. Prinz argues that owing to deficits in core negative emotions, such as fear and sadness, psychopaths cannot acquire empathetic distress or guilt and are consequently unable to make moral judgments $(2006,32)$. In his view, the relevant emotional deficits constitute the "root cause" of their antisocial behavior (ibid). 
Shaun Nichols $(2002,2004)$ takes a similar approach. According to Nichols, the empirical evidence suggests that psychopaths have impaired capacities for making moral judgment, but contra what rationalists might have us expect, the relevant deficit is a defective emotional response. Nichols cites psychopaths' difficulty with the Moral/Conventional Distinction Task as evidence of moral impairment and the clinical description of the psychopath's emotional deficits as evidence of emotional impairment. He argues that psychopaths' emotional deficits inhibit their ability to make "core moral judgments," where core moral judgments "are judgments that implicate 'Sentimental Rules,' or rules prohibiting actions that are independently likely to elicit strong negative affect." ${ }^{5}$ In his account, rationalist views seem ill suited to explain the psychopath's poor performance on the MCT, given that psychopaths seem rationally competent and very young children and many individuals with severe cognitive disabilities do well on the task (2002, 296).

Moral rationalists have sought to defuse the sentimentalist challenge by arguing that: (1) evidence that emotions play important roles in moral judgment and action does not undermine (all varieties of) moral rationalism, and (2) psychopaths have deficits in practical reason that might explain their moral impairments.

In support of (1), Kennett argues that rationalists can comfortably accommodate a significant role for sentiments in morality, noting that Immanuel Kant regarded "moral feeling" as a subjective precondition for "receptiveness to reason's constraints" (2002, 354). Kennett suggests several rationalist-friendly interpretations of the psychopath's emotional-moral impairment. Psychopaths seem to lack reverence for reason or, again, displeasure at cognitive dissonance - affective phenomena that may facilitate susceptibility to, and effective employment of, reason (2002, $355,2010,256) .^{6}$ In a similar vein, Heidi Maibom suggests that emotional deficits might impact the psychopath's moral abilities "through practical reason alone," thus leaving moral rationalism unscathed. If, for example, psychopaths' deficits in negative emotions inhibit moral education "through reward-punishment centered learning," as Prinz suggests, then a rationalist interpretation of the relevant moral impairment seems apt, notwithstanding the role played by emotion $(2010,8)$. After all, the ability to acquire knowledge via reward-punishment-centered learning is a rational ability.

Moral rationalists have also sought to defend their position by arguing directly for (2), the view that psychopaths also have rational deficits that might explain their moral impairment. Maibom, for example, highlights a host of cognitive difficulties that might inhibit the psychopath's capacity for practical reason. Psychopaths are notoriously impulsive, have inflated notions of their abilities, and have trouble adjusting their behavior in light of negative outcomes. In Maibom's account, these attentional problems, inaccurate self-estimates, and "reversal deficits" negatively impact the psychopath's abilities to will the necessary and sufficient means to his ends, to coordinate his intentions with foreseeable consequences of his actions, and to coherently universalize maxims $(2005,239,247)$. Maibom concludes that as these factors bear on one's competence in grasping and enacting moral duties, the psychopath's practical irrationality plausibly explains his moral impairment.

Similarly, Kennett argues that the psychopath is at best short-term instrumentally rational, lacking any coherent, extended conception of his ends and often failing to adopt reasonable means toward achieving his proclaimed ends $(2002,2006)$. The psychopath might profess to have lofty goals, but his goals are often both fleeting and unrealistic. Within the same day, a psychopath might form and give up his plan to become a professional athlete, deciding now to become a doctor - all while lacking the requisite skills and training (and any plans to acquire them) for either. Kennett also points out that psychopaths often employ "grossly disproportionate means to their immediate ends" $(2006,76)$. Think here of the psychopath who, wanting to 
buy beer for a party, decided to brutally assault and rob a service-station attendant rather than return home for his forgotten wallet. ${ }^{7}$

Marko Jurjako and Luca Malatesti (2016) review experimental results concerning the psychopath's performance on instrumental learning tasks, and they argue that peculiarities in the psychopath's performance are likely attributable to informational inaccessibility rather than impaired instrumental rationality. In other words, as they interpret the evidence, psychopaths' insensitivity to certain kinds of information may, in some cases, render them unaware of the means for their ends but not incapable of "willing the accessible means that are necessary or sufficient for accomplishing some end" (2016, 726).

Doubtless, psychopaths often successfully engage in means-end reasoning. Importantly, though, Kennett suggests that basic means-end reasoning does not suffice for rational agency, the "markers" of which include the capacities for normative reflection and rational self-control (2010, 254). She writes,

A person who could not reflect upon whether or not his desires provided 'reasons' for action, whose desires were entirely unresponsive to such reflection, or who could not be guided by the results of his deliberations, through exercises of planning and selfcontrol, would not count as a rational agent.

$(\text { ibid, 252) })^{8}$

The psychopath, being severely limited in his abilities to take an evaluative perspective on his desires and to delay their immediate satisfaction, seems to exemplify this rational defect. Drawing on child development research, Kennett explains that the capacities for normative reflection and rational self-control typically begin to emerge around the same time as the capacity for making the moral/conventional distinction, thus suggesting a link between psychopaths' rational deficits and their moral impairment (ibid, 253).

\subsection{Motivational judgment internalism and motivational judgment externalism}

Considerations about psychopathy have also entered into the debate between motivational judgment internalists and motivational judgment externalists. In its barest form, motivational judgment internalism (MJI) posits a necessary connection between moral judgments and moral motivation (Smith 1994; Roskies 2003). MJI is often construed in terms of the following thesis: If Agent A judges that $\Phi$-ing is morally wrong, then necessarily A will be motivated not to $\Phi$, or, again, if A judges that s/he morally ought to $\Phi$, then necessarily she will be motivated to $\Phi .{ }^{9}$

Motivational judgment externalism (MJE) is just the denial of MJI. According to motivational judgment externalists, moral judgments do not entail corresponding motivations. A common objection against MJI is the possibility of a "rational amoralist," someone who knows and understands the dictates of morality (and presumably makes moral judgments) but doesn't care about morality and is unmotivated to comply with moral norms (Brink 1989). The psychopath - who, in some understandings, seems similar to the rational amoralist - might then pose a challenge for proponents of MJI. ${ }^{10}$ Internalists have typically responded by insisting that psychopaths (sociopaths, etc.) don't really make moral judgments but only do so in "an inverted commas sense" and thus pose no threat to MJI (Smith 1994). ${ }^{11}$

As internalist replies to the psychopathy objection tend to employ many of the same arguments canvassed in section 2.1, we can afford to be relatively brief here. In support of their 
claim that psychopaths do not make moral judgments, theorists often cite the psychopath's poor performance on certain empirical measures and oddities in his use of moral language. Kennett and Cordelia Fine (2008), for example, discuss myriad studies that, in their account, suggest that psychopaths do not make genuine moral judgments. Familiarly, they note that psychopaths have significant difficulties drawing the moral/conventional distinction, forming value judgments without making exceptions of themselves, and correctly deploying moral concepts in conversation (2008, 174-178). ${ }^{12}$ Kennett and Steve Matthews (2008) raise similar points, adding that the psychopath's more general rational impairment renders him a poor candidate for the "rational amoralist." As they argue, psychopaths are only "very implausibly viewed as rationally unified agents," given their lack of facility with normative reasons (2008, 222, 224). Owing to poor self-regulation skills, shortened attention spans, and impoverished conceptions of their own well-being, psychopaths are unable to grasp, and to guide themselves by, the normative considerations that typically unify and sustain extended agency. We find evidence for this in their selfdestructive behaviors and erratic, contradictory speech (ibid, 223-224). Kennett and Matthews urge that these deficits are likely related to psychopaths' moral deficits, since moral agency and rational agency apparently go together in the normal case. Adducing child development studies, they conclude that since the higher-order cognitive capacities required for self-constitution and extended agency are the "same capacities that make us rationally susceptible to moral claims," it seems unlikely there exist rational amoral agents (ibid, 228).

Some have expressed skepticism about the psychopath's supposed inability to make genuine moral judgments. In responding to Kennett and Fine, for example, Roskies (2008) argues that the evidence suggests that psychopaths reason differently about moral norms but not that they altogether fail to make moral judgments. Roskies also doubts that the ability to draw moral/ conventional distinctions is necessary for making moral judgments. She writes, "Psychopaths are still cognizant of what is morally right and wrong. . . Even if their concepts are impaired, it is plausible that they are nonetheless moral concepts" (2008, 202). Relatedly, Walter SinnottArmstrong (2014) argues that the empirical evidence concerning psychopaths' abilities to make moral judgments is inconclusive. He suggests that the relevant studies often suffer from methodological limitations and sometimes yield mixed results - noting, for example, that psychopaths tend to perform well on a modified version of the MCT $(2014,195) .{ }^{13}$

Much of the dialectic turns on whether internalists and externalists can agree upon criteria for determining whether a moral judgment has been made that doesn't presuppose the presence or absence of moral motivation. Some have proposed that we can make headway by acknowledging that facility with moral concepts is at least necessary for moral judgment or, again, that we can use the MCT to help identify the key features of a distinctly moral judgment. ${ }^{14}$ As we have seen, however, theorists have questioned both the criteria themselves and the validity of the tools used to measure them.

\subsection{Morally responsible agency: rational competence versus moral competence}

Theorists have employed considerations about psychopathy to illuminate another important metaethical issue: the matter of which capacities are required for morally responsible agency.

Though many creatures might harm us, we only hold some of them morally responsible for their harmful actions. For example, lions, toddlers, and those in the grips of psychotic delusions may sometimes inflict harm, but we typically do not blame them for doing so. They are unable to fully grasp the nature of their actions and to exercise rational control over their behaviors. 
Thus, they are not appropriate candidates for the blaming and praising attitudes (e.g., resentment and gratitude) by which we hold one another morally responsible.

Psychopaths represent a more perplexing case. At the very least, psychopaths have some understanding of societal norms and how to comply with them. They know that theft and assault are grounds for legal punishment and sometimes show self-restraint in order to avoid such penalties. What's more, psychopaths often demonstrate awareness of moral expectations. They know, for example, that helping others is generally considered morally good while deceit is considered wrong. They sometimes use this knowledge to manipulate others, representing themselves in conversation as "generous" or "honest" to get what they want. These competences seem to set psychopaths apart from lions, toddlers, and those suffering from psychotic delusions.

In some accounts, psychopaths' rational capacities render them eligible candidates for blame. T.M. Scanlon, for example, claims that "a rational creature who fails to see the force of moral reasons" might be properly subject to moral criticism, provided he can "understand that a given action will injure others and can judge that this constitutes no reason against so acting" (1998, 288). Similarly, Matthew Talbert argues that despite being "morally blind," psychopaths are blameworthy for their actions because they are "capable of making decisions on the basis of judgments about reasons" (2008, 519). Talbert describes psychopaths as effective practical reasoners who can "count the pleasure of having a possession of yours as a reason to take it from you and ... form the judgment that nothing about the effect of this action on you is a reason to refrain from performing it" $(2008,522)$. In these views, owing to psychopaths' rational competence, their actions can express offensive judgments that legitimize blaming attitudes. ${ }^{15}$

Many theorists reject the view that mere rational competence - that is, facility with reasons in general - suffices for moral accountability. Gary Watson, for example, is among those who argue that moral accountability requires competence with moral reasons in particular. In this view, an otherwise rationally competent psychopath would be exempt from moral responsibility if he were unable to recognize moral reasons. ${ }^{16}$ This claim raises questions about the particular capacities required for the kind of recognition at issue. What must morally competent agents be able "to do" with moral reasons? And why should we think that psychopaths lack the relevant abilities? Watson employs an argument from moral communication (henceforth, AMC) to answer these questions.

Watson argues that resentment, along with other reactive attitudes by which we hold others morally accountable, "are incipiently forms of communication, which make sense only on the assumption that the other can comprehend the message" (1987, 264). He explains that resentment expresses a moral demand for reasonable regard and suggests that very young children and psychopaths may lack sufficient moral understanding to be proper recipients of the relevant demand (ibid, 271). ${ }^{17}$ Watson later elaborates on this position, describing psychopaths as "unreachable by the language of moral address" due to their inabilities to recognize moral demands (and the authority of those who address them) as intrinsically reason giving (2011, 309). In his view, psychopaths cannot see our demands that they refrain from harming us as anything but coercive pressures, supplying at best instrumental reasons to comply. Being unable to see the normative force of moral demands, psychopaths are infelicitous targets of resentment.

AMC has been endorsed by a number of theorists, many of whom emphasize the role of emotional capacities in giving uptake to moral address. ${ }^{18}$ Some stress the import of being able to feel guilt in response to (negative) reactive attitudes. ${ }^{19}$ David Shoemaker focuses on two broader emotional deficits that seem to underlie the psychopath's lack of guilt: his inabilities to care 
about others and, relatedly, to experience (a certain kind of) empathy. In Shoemaker's view, the capacity to care about others is necessary for being motivated to comply with the reasons exchanged in moral address $(2007,84)$. He also posits that since the emotional aspect of moral address calls on "the addressee to imaginatively step into the shoes of the other in order to feel what one has put him or her through," moral accountability requires the capacity for "identifying empathy" (2007, 93). Since the psychopath cannot care about the agent who addresses him with resentment, he cannot give the appropriate identifying empathetic response and is thus exempt from moral accountability (ibid; 2015, 146).

The capacities for caring and valuing often play central roles in accounts of morally responsible agency, and not just for proponents of AMC. Antony Duff, for example, argues that moral competence requires "a participant understanding" of at least some values (moral or not) where this involves a "creative capacity to understand the significance of the value . . . and to discuss, extend, and criticize its application" (1977, 195). Duff ties understanding the significance of values to emotional sensibilities and a practical commitment to the values in question, where the latter is explained in terms of seeing those values as providing reasons for action. He concludes that owing to deficits in these areas, the psychopath, while intellectually competent, is "seriously defective in practical understanding and rationality," and no more "answerable for his actions ... than ... a young child" (ibid, 199).

Carl Elliott and Grant Gillett take a similar approach, arguing that moral understanding involves the capacities "to create . . one's own moral rules and values," to justify them to oneself and others, and to apply them "imaginatively" by demonstrating insight into the interests of others and one's own weaknesses $(1992,57)$. Citing certain abnormalities in brain areas associated with higher-order cognitive processing, Elliott and Gillett suggest that the psychopath is unable to adequately integrate his "actions and intentions with his character and commitments to those around him" (ibid, 59-60). Consequently, psychopaths have difficulty forming "stable behaviour patterns as rational and social beings," and this explains their lack of self-regard and their inability to care about morality or other people (ibid, 63). ${ }^{20}$

Notice that Elliott and Gillett describe the psychopath's moral deficits in terms of a broader defect of practical reason. Moral understanding requires the capacity to value, which in turn, requires the capacity for integrated agency, extended over time. This supports a view that has become increasingly popular among responsibility theorists: psychopaths might have diminished moral accountability because they lack the capacities to adequately coordinate their intentions, make realistic, long-term plans, adjust their actions in light of negative outcomes, delay desire satisfaction, and engage in normative self-reflection (Litton 2008; Kennett and Matthews 2009; Levy 2014). ${ }^{21}$

Even those who deny that psychopaths are morally accountable often acknowledge that psychopaths have considerable rational capacities, some of which are morally relevant. Duff, for example, describes psychopaths as adept in areas of practical reason "having to do with a wide range of non-normative beliefs and reasoning" and in "short-term practical reasoning about the satisfaction of desires or impulses" $(2010,209)$. Watson claims that psychopaths are capable of a complex mode of reflective agency that distinguishes them from mere brutes. They can "get behind" the pain and mischief they cause, and this makes a difference for how we morally respond to them $(2011,316)$. In light of the considerable abilities that psychopaths do have, some theorists express skepticism about the claims that psychopaths lack the means to acquire moral knowledge or the capacities required for moral competence. ${ }^{22}$ In addition, some who deny that psychopaths are "morally accountable," and thus inapt targets of resentment, allow that they might be morally responsible in other senses. ${ }^{23}$ 


\section{Progress and future directions}

Having surveyed the relevant literature, we are now well positioned to see what insights we might glean from philosophical treatments of psychopathy and practical reason.

Let's start with a broad observation. In each of the preceding debates, we find some theorists who deem the psychopath "rationally competent" and an opposing group insisting that psychopaths lack the relevant competence, except in a deeply impoverished conception of practical rationality. As I will show, the arguments that develop from this dispute help to illuminate the richness of practical reason - and human agency more broadly - and suggest certain standards for an adequate theory of practical rationality. ${ }^{24}$

The relevant arguments implicate (roughly) four intersecting clusters of abilities that bear on our capacity for practical reason. Some arguments, for example, emphasize our cognitive sophistication. We are complex agents who require intricate coordination, planning, and imagination to successfully identify and pursue the means to our ends. Thus, the capacity for intelligent, goal-directed behavior may not suffice for practical rationality. Attention deficits, disorganized thinking, lack of foresight about the consequences of one's actions, and poor insight into one's own abilities may undermine one's capacity for practical reason.

The second cluster concerns our abilities to experience emotions and to engage in emotional processes. We are not just cognitively sophisticated beings, but we are also emotional beings. What's more, the affective dimension of our psychology is not alienated from practical reason. The debate between sentimentalists and rationalists underscores a now widely endorsed, but sometimes underappreciated, point: the distinction between cognitive capacities and emotional capacities is often nebulous, and even where we can distinguish between them, those capacities often work together to facilitate harmonious deliberation and action. Emotions can help to facilitate access to certain kinds of reasons, clarify reasons, or even serve as practical reasons themselves. ${ }^{25}$ Thus, emotional deficiencies might shield certain reasons from view and/or inhibit one's ability to act on such reasons.

The third cluster concerns our abilities to engage in normative reflection. We can step back and make judgments about our desires, beliefs, and reasons for action. We can guide our behavior in light of those evaluative judgments. We often eschew immediate rewards in favor of pursuing long-term ends that we deem more worthwhile. And we coordinate our intentions and plans accordingly, adjusting course as needed in response to mistakes and new information. The preceding debates invite us to consider how deficits in these areas might disrupt one's agency and interfere with one's ability to make, and to be moved by, normative judgments. If severe enough, such deficits would seem to constitute a considerable defect of practical reason.

The fourth cluster concerns our capacities as valuing agents. We not only make evaluative judgments that guide our actions, but we can engage with value in rich and constructive ways. We can take a "participant stance" that facilitates a more intimate connection with normative material in the world, allowing us to extend and apply our values "creatively." In valuing one's partner or one's career, for example, one comes to see those objects of value as imbued with a special kind of reason-giving force, and this helps us to understand the meaning that others' values have for them. And the same capacities that ground our abilities to care about, and to value, others also seem closely tied to our ability to value ourselves. ${ }^{26}$ Finally, further evidence of our dynamic engagement with normative material comes from our ability to bestow value on some object (for example, by loving it) - or, again, to create authority-based reasons for action by exercising normative powers, as we do when we make demands or certain kinds of commitments. ${ }^{27}$ Many of the arguments in the 
preceding debates suggest that the abilities to value in these ways - and to see the interests and authority of others as reason-giving in the relevant sense - are integral to the kind of practical rationality defining of creatures like us.

Taking seriously the multi-layered nature of practical reason has implications for what we should expect from a theory of practical rationality. Minimally, an adequate theory should not stand in tension with our remarkably complex rational natures. And all the better for a theory that helps to explain how specific aspects of our psychology interact to facilitate recognition and responsiveness to reasons for action. The debates canvassed here do not furnish us with a unified theory of practical reason, but they are rife with creative insights that raise interesting questions to keep in mind as we move forward. For example, are certain affective phenomena, such as the dispositions to experience displeasure at cognitive dissonance or regret in response to social censure, preconditions for receptivity to certain kinds of reasons? How, and to what extent, might deficits in fear and sadness obstruct moral learning? What role might positive emotions play in moral reasoning? Given that rational agency and moral competence "go together" in the normal cases, what explains the fact that the psychopath's distinctly moral deficits seem to be far more severe than his (general) rational defects? How do impaired capacities for normative reflection - or again, for valuing - threaten unified agency?

By pondering what may have "gone wrong" with the psychopath, we might gain a better grasp of how practical reasoning ideally operates in rational persons. In this vein, philosophical treatments of psychopathy have laid the ground for considering how other forms of psychopathology might inform moral psychology. For example, given that narcissists seem to value themselves and yet lack the capacity to value others, how do they fare (compared to psychopaths and the general population) as practical reasoners? Do disorders with certain pronounced cognitive impairments, such as attention and memory disorders, tend to have corresponding emotional abnormalities? And if so, how does this combination of features impact moral agency and practical rationality more broadly?

Given that practical reason consists in a suite of abilities that facilitate rational agency, we have a stake not only in identifying those abilities and understanding how they interact but also in determining their respective significance. Discussions of psychopathy and practical reason can help to anchor and guide our thinking about this important issue. First, supposing our capacity for practical reason, in part, grounds our statuses as rights-bearers and morally responsible agents, we might wonder which specific abilities are required for the relevant statuses. Relatedly, as the case of the psychopath demonstrates, there are some individuals who have some, but not all, of the relevant abilities. How do we determine whether we should hold such individuals legally responsible for their infractions or, again, whether they have rights that we are bound to respect (such as the right to refuse medical treatment)? And if narrow rational defects can engender more global moral impairment, might our own occasional failures of practical rationality be morally significant in unobvious ways? In attempting to answer these questions, we move beyond (or, perhaps better, expand) the boundaries of practical reason theory, now engaging with theories of responsibility and moral standing, as well as exploring implications for our social, legal, and medical practices.

Mining these debates for insights has raised more questions than it has answered, but there is something to be said for identifying the right questions to ask. The preceding discussion makes plain our interest in acknowledging that practical reason is not a unary capacity but involves a suite of abilities that engage different aspects of our psychology and work together to help constitute us as unified agents. Because they can facilitate rich engagement with others and help 
secure our passage into the realm of rights and responsibilities, we have a stake in determining how specific capacities might matter for us. As I have argued, the previous debates can help guide our thinking about the nature, function, and significance of practical reason and aid our understanding of the kind of beings we are.

\section{Notes}

1 There is a worry that in making general - and, in particular, moral - claims about "the psychopath," we risk inappropriately marginalizing large groups of actual people. That is not my intention. I take it that not all who have been diagnosed with psychopathy neatly fit the following criteria, and so we should be cautious about indiscriminately extending potentially harmful judgments based on this model to those who identify as psychopaths. Also, it is not without some regret that I use the term "psychopath" here, as opposed to "psychopathic individual," and I do so only for the purpose of maintaining continuity and cohesion with the relevant literature. I thank Hanna Pickard for helpful discussion on this point.

2 Consequently, I will use masculine pronouns when referring to psychopaths.

3 For a discussion of research indicating that psychopaths perform well on a modified version of the MCT, see Aharoni et al. 2012. Some theorists remain unconvinced that the newer studies conclusively demonstrate the psychopaths' (unimpaired) facility with the relevant distinction, since the amended version of the task seems notably easier than the original version (see, for example, Kumar 2016).

4 See also Michael Smith 1994.

5 Nichols explains that core moral judgments are guided by an "internally represented body of information, a "normative theory' prohibiting behavior that harms others" $(2002,16)$ and "some affective mechanism that is activated by suffering in others" (ibid, 18).

6 Kennett, following her interpretation of Kant, suggests that reverence for reason, understood as "the concern to act in accordance reason," is the core moral motive and suggests that the psychopath's "indifference to reason is the key to his behavior" $(2002,355)$. For an insightful response to Kennett on this point, see Victoria McGeer 2008.

7 Kennett and Steve Matthews discuss this case in a later work, describing the psychopath's actions as "not just immoral" but "stupid" (2008, 225).

8 Importantly, not all would agree that the defects Kennett identifies here constitute practical irrationality. First, one might draw a distinction between structural rationality and responsiveness to reasons (see, for example, John Broome's entry in this volume). Second, even those who associate practical rationality with reasons-responsiveness might deny that failure to engage in normative reflection represents irrationality, as opposed to a mere failure to exercise one kind of rational capacity. Thanks to Kurt Sylvan for prompting me to highlight this point.

9 Some theorists have offered weaker formulations. Michael Smith's preferred version holds that if Agent A judges that $\Phi$-ing is wrong, then either A will be motivated not to $\Phi$ or A is practically irrational $(1994,61,2008,211)$.

10 Adina Roskies (2003) cited research findings on a group of patients with "acquired sociopathy" as evidence against MJI. According to Roskies, following injuries to the ventromedial prefrontal cortex area of the brain, these patients continued to have normal moral beliefs and to make moral judgments, but they were no longer inclined to act in accordance with those beliefs and judgments, thus falsifying MJI $(2003,63)$.

11 We find sentimentalists on both sides of the debate. Prinz, for example, suggests that psychopaths "furnish internalists with a useful piece of supporting evidence," insofar as their co-occurrence in moral motivation and moral competences appears to be linked $(2007,44)$. Nichols argues that considerations about psychopathy suggest against some varieties of internalism, including "conceptual judgment internalism about moral judgment" and "empirical internalism about harm-norm judgment" (2004, 109-115).

12 In a later work, Kennett argues that psychopaths lack competence with moral concepts, as they are not "conversable" with the relevant terms $(2010,246)$.

13 For discussion of recent empirical work on psychopathy and moral judgment, see Sinnott-Armstrong 2014, 193-199.

14 See, for example, Kennett 2010; Kumar 2016.

15 In a recent modification and extension of her earlier (2003) work, Patricia Greenspan argues that even if they cannot understand moral reasons as such, typical psychopaths are morally responsible insofar as 
their behavior can express ill will, but they may be less than fully blameworthy for their moral infractions owing to impairments in behavior control (2016).

16 See also Wallace 1994; Shoemaker 2007, 2015; Fischer and Ravizza 1998. Paul Litton argues that there is no "meaningful disagreement" between mere rational competence theorists and moral competence theorists, since "the capacity for rational self-governance entails the capacity to comprehend and act on moral considerations" $(2008,351)$. For arguments that moral responsibility turns on the possession of moral knowledge rather than any particular capacity, see Elinor Mason 2017.

17 Here, Watson follows P.F. Strawson 1962. Watson also raises the case of Robert Harris, a man who callously murdered two innocent teenage boys, but was himself a victim of brutal abuse from a very young age. Watson doesn't identify Harris as a psychopath but uses his case to consider whether some agents "of evil," being unfit for moral dialogue, are inappropriate targets of resentment due to "constraints on moral address" (1987, 268-274).

18 See Scanlon 2008; Smith 2013; Talbert 2008, 2012 for rejections of the argument from moral communication. See Coleen Macnamara 2015 for a detailed response to these challenges.

19 Macnamara argues that a function of reactive attitudes is securing uptake from their addressees and since "uptake of [resentment] amounts to feeling guilt and expressing it via amends," eligible targets of resentment must be able to feel guilt $(2015,212)$. Stephen Darwall argues that appropriate addressees of resentment (and its implicit demand) must be assumed to able to "make the same demands of, themselves through acknowledging their validity as in self-reactive attitudes like guilt" (2006, 79). For Darwall, this ability is a matter of competence with the "second-personal reasons" exchanged in moral address, where he describes such reasons as agent-relative reasons "whose validity is grounded in presupposed normative relations between persons" $(2006,78)$.

20 Watson (2013) proposes that the common ground of the psychopath's prudential and moral impairments is an incapacity for a particular kind of normative orientation. Interestingly, Watson's proposal concerns the psychopath's inability to value, where valuing includes "having standards for action, intention, and desire that ... serve as the basis for self-criticism and correction" (2013, 275-276).

21 Interestingly, Kennett and Matthews (2009) suggest that psychopaths have an impaired capacity for “mental time travel." Neil Levy (2014) takes up this idea, arguing that the psychopath's difficulty with mental time travel obstructs his grasp of moral concepts, such as personhood (and what it means to harm persons), and reduces his moral responsibility.

22 See, for example, Vargas and Nichols 2007; Brink 2013.

23 Watson and Shoemaker, for example, both hold that psychopaths may be morally responsible in the "attributability sense," a sense that tracks the relationship between a person's actions and her character (Watson 2011; Shoemaker 2015). Shoemaker delineates a third responsibility category on which psychopaths are sometimes responsible: "answerability," which concerns the agent's ability to "respond to others' demands for justification by citing their judgments about the worth of some reasons over others" $(2015,27)$. For an argument against the idea that psychopaths (at least as they are often characterized in the philosophical literature) are even attributability-responsible, see Nelkin 2015. For an argument that, on some descriptions, psychopaths may not even be able to "act for reasons," see Jaworska 2017.

24 Notice here that practical rationality refers to a capacity as opposed to the property that an attitude or act has when compliant with requirements of rationality. For more on this distinction, see John Broome's entry in this volume.

25 See Patricia Greenspan (2004), along with her entry in this volume, for detailed discussions of the role of emotion in practical reason.

26 For a Kantian approach to this idea, see Christine Korsgaard 1996.

27 For recent, illuminating work on normative powers, see Ruth Chang 2013.

\section{References}

Aharoni, E., Sinnott-Armstrong, W. and Kiehl, K. (2012) "Can Psychopathic Offenders Discern Moral Wrongs? A New Look at the Moral/Conventional Distinction,” Journal of Abnormal Psychology, 121(2): 484-497.

Blair, R. J. (1995) “A Cognitive Developmental Approach to Mortality: Investigating the Psychopath," Cognition, 57(1): 1-29.

. (2008) "The Cognitive Neuroscience of Psychopathy and Implications for Judgments of Responsibility," Neuroethics, 1(3): 149-157. 
Brink, D. (1989) Moral Realism and the Foundations of Ethics. New York: Cambridge University Press.

- (2013). "Responsibility, Incompetence, and Psychopathy," Lindley Lecture, 53: 1-41.

Chang, R. (2013) "Commitment, Reasons, and the Will," in R. Shafer-Landau (ed.) Oxford Studies in Metaethics, Vol. 8. Oxford: Oxford University Press, 74-113.

Cleckley, H. (1976) The Mask of Sanity. St. Louis, MO: C.V. Mosby Co.

Darwall, S. L. (2006) The Second-Person Standpoint: Morality, Respect, and Accountability. Cambridge, MA: Harvard University Press.

Duff, A. (1977) "Psychopathy and Moral Understanding," American Philosophical Quarterly, 14(3): 189-200. . (2010) "Psychopathy and Answerability," in L. Malatesti and J. McMillan (eds.) Responsibility and Psychopathy: Interfacing Law, Psychiatry and Philosophy. Oxford: Oxford University Press, 199-212.

Elliott, C. and Gillett, G. (1992) “Moral Insanity and Practical Reason,” Philosophical Psychology, 5(1): 53-67.

Fischer, J. M. and Ravizza, M. (1998) Responsibility and Control: A Theory of Moral Responsibility. Cambridge: Cambridge University Press.

Gill, M. B. (2007) “Moral Rationalism vs. Moral Sentimentalism: Is Morality More Like Math or Beauty?” Philosophy Compass, 2(1): 16-30.

Greenspan, P. S. (2003) "Responsible Psychopaths," Philosophical Psychology, 16: 417-429.

—. (2004) "Practical Reasoning and Emotion," in A. R. Mele and P. Rawling (eds.) The Oxford Handbook of Rationality. Oxford: Oxford University Press, 206-221.

- (2016) "Responsible Psychopaths Revisited," Journal of Ethics, 20: 265-278.

Hare, R. D. (1993) Without Conscience: The Disturbing World of the Psychopaths Among Us. New York, NY: Guilford Press.

Jaworska, A. (2017) "Holding Psychopaths Responsible and the Guise of the Good," in S. M. Liao and C. O’Neil (eds.) Current Controversies in Bioethics. London, UK: Routledge, 66-77.

Jurjako, M. and Malatesti, L. (2016. "Instrumental Rationality in Psychopathy: Implications from Learning Tasks," Philosophical Psychology, 29(5): 717-731.

Kennett, J. (2002) “Autism, Empathy and Moral Agency,” Philosophical Quarterly, 52(208): 340-357. $69-82$.

. (2006) "Do Psychopaths Really Threaten Moral Rationalism?” Philosophical Explorations, 9(1):

(2010) "Reasons, Emotion, and Moral Judgment in the Psychopath," in L. Malatesti and J. McMillan (eds.) Responsibility and Psychopathy: Interfacing Law, Psychiatry and Philosophy. Oxford: Oxford University Press, 243-260.

Kennett, J. and Fine, C. (2008) "Internalism and the Evidence from Psychopaths and 'Acquired Sociopaths," in W. Sinnott-Armstrong (ed.) Moral Psychology, Volume 3: The Neuroscience of Morality: Emotion, Brain Disorders, and Development. Cambridge, MA: MIT Press, 173-190.

Kennett, J. and Matthews, S. (2008) "Normative Agency," in K. Atkins and C. Mackenzie (eds.) Practical Identity and Narrative Agency. New York, NY: Routledge.

- . (2009) "Mental Time Travel, Agency and Responsibility," in M. Broome and L. Bortolotti (eds.) Psychiatry as Cognitive Neuroscience: Philosophical Perspectives. Oxford: Oxford University Press, 327-349.

Kiehl, K. and Buckholtz, J. W. (2010) "Inside the Mind of a Psychopath," Scientific American Mind, 21(4): 22-29.

Korsgaard, C. (1996) The Sources of Normativity. Cambridge: Cambridge University Press.

Kumar, V. (2016) "Psychopathy and Internalism," Canadian Journal of Philosophy, 46(3): 318-345.

Levy, N. (2014) "Psychopaths and Blame: The Argument from Content," Philosophical Psychology, 27(3): $351-367$.

Litton, P. (2008) "Responsibility Status of the Psychopath: On Moral Reasoning and Rational SelfGovernance," Rutgers Law Journal, 39(349): 350-392.

Macnamara, C. (2015) "Blame, Communication, and Morally Responsible Agency," in R. Clark, M. McKenna, and A. Smith (eds.) The Nature of Moral Responsibility. Oxford: Oxford University Press, 211-236.

Maibom, H. L. (2005) "Moral Unreason: The Case of Psychopathy," Mind and Language, 20(2): $237-257$.

- (2010) "Rationalism, Emotivism, and the Psychopath," in L. Malatesti and J. McMillan (eds.) Responsibility and Psychopathy: Interfacing Law, Psychiatry and Philosophy. Oxford: Oxford University Press, 227-242.

Mason, E. (2017) “Moral Incapacity and Moral Ignorance," in R. Peels (ed.) Perspectives on Ignorance from Moral and Social Philosophy. Oxford: Oxford University Press. 
McGeer, V. (2008) "Varieties of Moral Agency: Lessons from Autism (and Psychopathy)," in W. SinnottArmstrong (ed.) Moral Psychology, Volume 3: The Neuroscience of Morality: Emotion, Brain Disorders, and Development. Cambridge, MA: MIT Press, 227-258.

Nelkin, D. K. (2015) "Psychopaths, Incorrigible Racists, and the Faces of Responsibility," Ethics, 125(2): 357-390.

Nichols, S. (2002) “How Psychopaths Threaten Moral Rationalism,” The Monist, 85(2): 285-303.

- (2004) Sentimental Rules: On the Natural Foundations of Moral Judgment. Oxford: Oxford University Press.

Prinz, J. (2006) “The Emotional Basis of Moral Judgments," Philosophical Explorations, 9(1): 29-43.

- (2007) The Emotional Construction of Morals. Oxford: Oxford University Press.

Roskies, A. (2003) "Are Ethical Judgments Intrinsically Motivational? Lessons From 'Acquired Sociopathy,"” Philosophical Psychology, 16(1): 51-66.

- (2008) "Internalism and the Evidence from Pathology," in W. Sinnott-Armstrong (ed.) Moral Psychology, Volume 3: The Neuroscience of Morality: Emotion, Brain Disorders, and Development. Cambridge, MA: MIT Press, 191-206.

Scanlon, T. M. (1998) What We Owe to Each Other. Cambridge, MA: Harvard University Press.

- (2008) Moral Dimensions: Permissibility, Meaning, Blame. Cambridge, MA: Harvard University Press.

Shoemaker, D. (2007) "Moral Address, Moral Responsibility, and the Boundaries of the Moral Community," Ethics, 118(1): 70-108.

- (2015) Responsibility from the Margins. Oxford: Oxford University Press.

. (2014) "Do Psychopaths Refute Internalism?" in S. Thomas (ed.) Being Amoral: Psychopathy and Moral Incapacity. Cambridge, MA: MIT Press, 187-208.

Smith, A. (2013) "Moral Blame and Moral Protest," in D. Justin Coates and N. Tognazzini (eds.) Blame: Its Nature and Norms. Oxford: Oxford University Press, 27-48.

Smith, M. (1994) The Moral Problem. Malden, MA: Blackwell.

- (2008) “The Truth about Internalism," in W. Sinnott-Armstrong (ed.) Moral Psychology, Volume 3: The Neuroscience of Morality: Emotion, Brain Disorders, and Development. Cambridge, MA: MIT Press, 207-216.

Strawson, P. F. (1962) "Freedom and Resentment," in G. Watson (ed.) Proceedings of the British Academy, Volume 48: 1962. Oxford: Oxford University Press, 1-25.

Talbert, M. (2008) "Blame and Responsiveness to Moral Reasons: Are Psychopaths Blameworthy?” Pacific Philosophical Quarterly, 89(4): 516-535.

- (2012) "Moral Competence, Moral Blame, and Protest," The Journal of Ethics, 16(1): 89-109.

Turiel, E. (1983) The Development of Social Knowledge: Morality and Convention. Cambridge: Cambridge University Press.

Vargas, M. and Nichols, S. (2007) "Psychopaths and Moral Knowledge," Philosophy, Psychiatry, and Psychology, 14(2): 157-162.

Wallace, R. J. (1994) Responsibility and the Moral Sentiments. Cambridge, MA: Harvard University Press.

Watson, G. (1987) "Responsibility and the Limits of Evil: Variations on a Strawsonian Theme," in F. Schoeman (ed.) Responsibility, Character, and the Emotions. Cambridge: Cambridge University Press, 256-286.

- (2011) "The Trouble with Psychopaths," in Reasons and Recognition: Essays on the Philosophy of T.M. Scanlon. Oxford: Oxford University Press, 307-323.

- (2013) "Psychopathic Agency and Prudential Deficits," Proceedings of the Aristotelian Society, 113: 269-292. 